\title{
ARE WORKERS DOMINATED?
}

\author{
Tom O'Shea
}

$\prod$

ISTEN to what workers in London say about their jobs. In a shambolic 3-D printer manufacturing company, an employee complains about "arbitrary $J$ management decisions," including unplanned sackings and hasty changes to working time and pay. ${ }^{1}$ A temp at a supermarket distribution center says their shifts get canceled at short notice with little compensation, while adding that management can get temps to work faster by means of an "arbitrary" hiring process for the "carrot of a permanent job." According to a care worker, casualization has led to greater precarity for their colleagues, such that "current support workers are dependent on the good will of their employer." 3 These workers are each objecting to arbitrary power.

This language should be immediately familiar to political philosophers, since opposition to arbitrary power is a perennial theme of civic republican accounts of domination. But are these workers genuinely dominated? They choose to work for their employers, enjoy protection under the law, and possess the legal right to quit. Do they really lack the freedom republicans hold dear? I shall show how employers can and often do deprive workers of this republican freedom. Getting to grips with the nature of power over workers and job seekers does, however, require some conceptual innovation. My goals are to demonstrate that the leading republican theory of domination falls short in this respect, and to propose a capabilitarian and structural account of domination that sheds greater light on the mechanics of power in the workplace and labor market.

We shall see that the voluntariness of labor contracts and the limits on employer authority introduced by labor law do not preclude arbitrary power over workers. Yet, it is much harder to say when this amounts to arbitrary power to interfere, which is often treated as a necessary condition of domination. The orthodox account of domination adopted by neo-republicans like Philip Pettit sputters out when it encounters the turbulent history of labor struggle, since

1 Anonymous, "Soldering On."

2 Anonymous, "Don't Breakdown!"

3 Anonymous, "Careless." 
it relies on a form of cultural contextualism about what counts as interference, which cannot accommodate fierce disagreements between workers and bosses about the baseline choices workers can expect. However, the republican critique of domination can be reframed in terms of capabilities rather than interference, and this opens the door to an alternative account of domination as the arbitrary power to determine access to the capabilities needed to stand in relationships of civic equality. While this capabilitarian theory of civic domination offers a more tractable criterion for measuring domination, it neglects the possibility that dominating power is not always concentrated in the hands of a single employer. So, I show how this account of civic domination can be supplemented in order to encompass the domination to which workers and job seekers can be exposed as a result of their socio-structural position in the economy. ${ }^{4}$

\section{ON DOMINATION}

The aim of republican conceptions of domination has been to account for the unfreedom that arises from relationships within which a person falls under the power of a master (in potestate domini). ${ }^{5}$ Slaves are dominated, for instance, since they are subject to the will of their masters. This subjection has often resulted in forced labor; however, in principle, actual compulsion is not necessary for a dominating relationship: the kindly master who does not interfere with their slave remains a master all the same. Cicero captures something of this idea when he tells us that the most miserable aspect of slavery is that "even if the master happens not to be oppressive, he can be so should he wish." 6 Similarly, when the legal doctrine of coverture granted a husband the discretion to prevent his wife from holding property, obtaining an education, or entering a contract-including earning a wage for herself-then she was dominated whether or not the husband was inclined to exert his authority, since the fact that he could do so whenever he wished was sufficient to subject the wife to his will. ${ }^{7}$

Pettit, the leading contemporary republican philosopher, has made several

4 Our focus will be paid work in the formal economies of liberal democratic states, in which workers enter into voluntary contracts with employers to sell their labor-power. This narrow conception of work leaves aside unpaid reproductive activities, subsistence work, forced labor, volunteering, and so on. This is for analytical convenience rather than any intention to exclude these other activities from the category or esteem of genuine work. Similarly, we will pass over the converse question of whether workers dominate employers. For discussion, see Taylor, Exit Left, 60.

5 See Skinner, "Freedom as the Absence of Arbitrary Power," 86; Digest of Justinian, I.6.1, 18.

6 Skinner, "Classical Liberty and the Coming of the English Civil War," 10.

7 Jugov, “Systemic Domination as Ground of Justice," 9. 
influential attempts to characterize domination in a more exacting fashion than these examples alone allow. This is the most well-known definition:

Someone dominates or subjugates another, to the extent that

1. they have the capacity to interfere

2. on an arbitrary basis

3. in certain choices that the other is in a position to make. ${ }^{8}$

The most slippery term here is "arbitrary," which has been subject to a number of competing interpretations. ${ }^{9}$ Pettit now prefers to talk of domination as "exposure to another's power of uncontrolled interference" in order to avoid some of the misleading connotations of arbitrariness. ${ }^{10}$ But the fundamental coordinates of the concept remain much the same: domination can be present without actual interference occurring, whereas domination is absent when the ability to interfere is suitably regulated or constrained.

Why should we care about this domination? The republican answer is that it makes people unfree. Someone who is dominated cannot know their choices are secure from interference at the hands of individuals or institutions with unchecked power over them. Consequently, they are able to act only at the indulgence of others. This not only undermines their freedom but can also begin to warp their character-encouraging the dominated to get into the habit of fawning over or cowering from those who could intrude in their lives. Domination, so understood, can foster a servile and pliant disposition, which is why republicans identify a "tendency of the enslaved to act with slavishness."11

My goal is to determine whether domination occurs in the workplace or labor market, and this might seem relatively simple, since we only have to figure out whether the decisions of workers and job seekers can be arbitrarily interfered with. Moreover, there are some plausible prima facie grounds for thinking that workers are subject to such arbitrary power. Most workplaces have a hierarchical structure that allows bosses and managers to exercise a wide-ranging discretionary authority to hire and fire, as well as granting them the power to shape job roles, work pace, company policy, and the working environment. These considerations lead some republicans and sympathetic fellow travelers to conclude that domination is a real threat to many workers. For example, Elizabeth Anderson tells us that employers typically enjoy authority that is "sweeping, arbitrary, and unaccountable," with workers occupying "a state of republican unfreedom,

8 Pettit, Republicanism, 52.

9 Lovett, "What Counts as Arbitrary Power?"

10 Pettit, On the People's Terms, 28.

11 Skinner, "Freedom as the Absence of Arbitrary Power," 92. 
their liberties vulnerable to cancellation without justification, notice, process, or appeal." ${ }^{12}$ But we should not rush to such conclusions too hastily, since there are a number of reasons for denying that domination is commonplace in modern workplaces or labor markets.

\section{DO EMPLOYERS HAVE ARBITRARY POWER?}

Skeptics may deny the power of employers is sufficiently arbitrary to constitute domination-doubting that it qualifies as uncontrolled or unaccountable. The first reason to entertain such doubts stems from the voluntariness of labor contracts: the fact that workers must agree to work for their employers. Someone has to choose to take a job before their boss can start ordering them around, and this distinguishes employers in capitalist economies from slave masters or seignorial lords whose laborers were bound to them. This need to secure the agreement of workers makes it less plausible to characterize power over them as entirely arbitrary, since this power does not rest solely upon the will of the employer but also the decision of workers to enter into labor contracts (as well as to not subsequently quit). There is historical precedent for this verdict in the scorn of some American abolitionists toward the very idea of wage slavery. These abolitionists were uncomfortable with the implication that the shift from chattel slavery to waged labor had simply exchanged one form of domination for another. We instead find them stressing the importance of contractual agreement in underpinning the newfound freedom of emancipated slaves, whom they laud as "Freedmen at work as independent laborers by voluntary contract!"13

We should, however, reject the claim that a voluntary labor contract precludes arbitrary power. Considering another example of domination that comes about by means of agreement should help us see why. Someone who gives or sells themselves into slavery can do so consensually-for protection, subsistence, or money. ${ }^{14}$ In straitened circumstances, this might well be the best available option, chosen both rationally and willingly. But it is a loss of freedom in exchange for something valued more highly, and the voluntariness of the exchange

Anderson, Private Government, 54, 64. See also Hsieh, "Rawlsian Justice and Workplace Republicanism”; González-Ricoy, “The Republican Case for Workplace Democracy”; Breen, "Freedom, Republicanism, and Workplace Democracy." For other civic republican engagement with political economy, see Dagger, "Neo-Republicanism and the Civic Economy"; Pettit, "Freedom in the Market"; White, "The Republican Critique of Capitalism"; MacGilvray, The Invention of Market Freedom; Anderson, "Equality and Freedom in the Workplace"; Gourevitch, From Slavery to the Cooperative Commonwealth; Roberts, Marx's Inferno. Garrison, "Is the Cause Onward." See also Cunliffe, Chattel Slavery and Wage Slavery. Patterson, Slavery and Social Death, 130-31. 
does not mean the resulting power is neither arbitrary nor dominating. Willingly handing over control to a new master does not itself ensure their freshly acquired power is so limited, accountable, or contestable that it no longer has an arbitrary character. Similarly, voluntarily accepting the authority of an employer need not establish sufficiently strong constraints on their power to make it nonarbitrary. Of course, the live possibility of workers refusing to take up or remain in a job can still exert a disciplinary pressure on an employer, which may restrict their room for maneuver in how they can routinely treat their staff. But it does not comprehensively close down their discretionary power-especially that held over those workers who have a compelling reason to stay in their jobs, such as a lack of better options. Therefore, workers do not possess immunity from the arbitrary power of employers simply by virtue of having agreed to work for them.

Legal constraints outside the labor contract provide a second reason to doubt the power of employers is arbitrary enough to be dominating. Think of measures making racial, gender, and/or disability discrimination illegal in recruitment; mandating a minimum wage; limiting working time; requiring rest breaks; outlawing sexual harassment; restricting unfair dismissal; guaranteeing rights to join a trade union; establishing minimum safety standards; and so on. While these protections are far from universal, when present they each restrict the untrammeled authority of employers. This significantly conditions the power to which workers and job seekers are subject-further constricting the free play of employers beyond the limits placed upon them by the need to establish and maintain a labor contract with their workers.

Employer power does not, however, have to be entirely unchecked to be arbitrary. While the law fences employers in to some degree, there are many areas where they typically have authority to act as they see fit, or in which legal regulation allows them great latitude within certain bounds: for instance, determining work pace, altering job roles, directing company policy, and shaping the physical and social environment where work takes place. Even in those areas that are supposed to be tightly legally governed, such as wrongful dismissal and minimum wages, the effective ability to enforce the law is often lacking, especially where union representation is low and the threat of employer retaliation is hard to defend against. Furthermore, the social position occupied by managers often allows them to enjoy considerable informal authority, which can enable them to goad staff into working longer, harder, and in worse conditions than the law itself allows. Thus, while legal protections shape aspects of employment relationships, these are not always effective, and inevitably leave unregulated a significant subset of the powers of employers over their workers.

Our initial impetus for supposing some workers might be dominated was 
their own testimony concerning the arbitrary power of employers over recruitment, wage-setting, and control of the labor process. Examples abound of the draconian use of such powers, including refusals of toilet breaks, bans on causal chatting, mandatory unpaid after-work inspections, suspicionless drug testing, and firings of union organizers. ${ }^{15}$ But we have met two objections to characterizing the power of employers as arbitrary: the voluntariness of labor contracts and the constraints imposed by labor law. Each places some limits on the authority of employers but still leaves considerable scope for workers to find themselves subject to the will of their bosses. So, the control over power that they grant to workers is at best incomplete. Domination is not therefore ruled out on the grounds of a lack of arbitrariness in employer power.

\section{CAN EMPLOYERS INTERFERE?}

Civic republicans usually understand domination as the arbitrary power to interfere. ${ }^{16}$ This opens up a second line of attack for those skeptical that workers are dominated: they can concede that employers possess arbitrary power while maintaining that this is not a power of outright interference. Few bosses can consistently beat or imprison their workers. Nor is an employer able to compel someone who resigns or refuses to sell their labor to them in the first place. So, in what sense, if at all, are employers able to interfere with workers and job seekers?

Pettit identifies interference with an intentional removal, replacement, or misrepresentation of the choices available to someone, which worsens their choice-situation. ${ }^{17}$ This encompasses not only physical coercion, restraint, or obstruction but also punishment and threats, as well as manipulation and deception. Among examples of a power of interference would be capacities for violence, blackmail, or dishonesty whose exercise negatively affected the deliberative capacities or choices available to someone. The choices vulnerable to interference that Pettit takes to be most salient for a republican ideal of non-domination are those underpinning the basic liberties, understood as "the sphere of choice required for being able to function in the local society." 18

Some economists and philosophers offer reasons to doubt that employers wield powers of interference. Take Armen Alchian and Harold Demsetz, who claim that firms have "no power of fiat, no authority, no disciplinary action any

Anderson, Private Government, xix.

Pettit, Republicanism, 52; Honohan, Civic Republicanism, 184; Laborde, Critical Republicanism, 2; cf. Lovett, A General Theory of Domination and Justice, ch. 3. 
different in the slightest degree from ordinary market contracting between any two people." ${ }^{19}$ They recognize that employers can terminate the relationship with a worker but treat this as no different from someone who chooses to shop with a different grocer. Thus, they conclude, "No authoritarian control is involved; the arrangement is simply a contractual structure subject to continuous renegotiation." ${ }^{20}$ Pettit's own account of market exchange does not make a radical departure from this analysis, insofar as he claims that market exchanges are voluntary agreements among people who accept "reciprocal offers of reward in the event of acting as they require of one another," and that "such offers of reward are not coercive in the manner of penalties or threats of penalty." ${ }^{21}$ So understood, ordinary market offers do not constitute interference, because they simply add a new choice to someone's option set rather than removing, replacing, or misrepresenting their existing choices.

Consider the implications of Pettit's discussion of market exchange for the control of employers over the recruitment process, including hiring, contract renewal, and assigning shifts. We might think the ability to refuse someone a job resembles a power of interference. But Pettit's account of the market emphasizes that an offer of a job remains an offer. Ordinarily, the power to withhold an offer is not itself a power to interfere with someone's choices, since offers expand rather than contract the choices available to people. Seen in this light, the power of employers over recruitment would not allow them to interfere with existing choices but only determine whether an additional choice is added-namely, the choice to enter or extend a working relationship with this employer. Thus, these powers would not be dominating, irrespective of how arbitrarily they could be exercised.

Civic republicans do, however, acknowledge that some omitted market offers constitute interference. Think of the pharmacist who refuses to sell someone an urgently required medicine without good reason or only at a hugely inflated price. Pettit counts this refusal as interference due to the degree to which the array of choices available to the sick person is worsened with respect to "the received benchmark." ${ }^{22}$ This account holds that interference presupposes a prior baseline relative to which the effects of any intentional removal, replacement, or misrepresentation of choices must be understood. Pettit thus talks of "inter-

Alchian and Demsetz, "Production, Information Costs, and Economic Organization," 777. For further discussion, see Anderson, Private Government, 54-56.

Alchian and Demsetz, "Production," 794.

Pettit, "Freedom in the Market," 143. Pettit acknowledges that this is a highly idealized understanding of markets, which will not apply in conditions approaching "wage slavery," but he fails to say whether he thinks the latter conditions prevail in our actual world. 
ference by the benchmark of what is normal," telling us that "context fixes the baseline by reference to which we decide if the effect is indeed a worsening," and referring us to "the facts as they are seen through the local cultural lens" in making such judgments. ${ }^{23}$

This is a contextualist account of interference that relies on local cultural standards to determine whether a choice situation is worsened relative to a baseline normal position. What does it imply for power in the workplace and job market? Pettit suggests that workers will be dominated when they enter employment contracts under the "spectre of destitution." ${ }^{24}$ For example, an employer can possess a power of interference over a worker under monopsony conditions who has few social welfare guarantees, whereas they will be further from doing so when many non-colluding employers are competing for the worker's labor or if there is a strong social safety net for the unemployed. Therefore, Pettit's contextualism can make room for exceptions to his otherwise sanguine view of marketized relationships, which allows that there are circumstances when powers of interference and relationships of domination do emerge in the workplace and labor market.

\section{OUT OF CONTEXT}

Contextualism is most plausible against the backdrop of high levels of agreement about the baseline choices against which we can measure whether interference takes place. But such consensus is elusive in actual discussions of work. For instance, there are rarely any uncontested "received benchmarks" or "local cultural standards" available to determine whether a failure to offer someone work worsens their choice-situation, since there is little agreement about when it is either normal or reasonable to expect an employer to hire someone, renew their contract, or maintain their hours. The inconclusive exchange between Marion Cotillard's character and her boss in the 2014 film Two Days, One Night exemplifies such disagreements:

Sandra: I can't let someone be laid off so I can come back.

Dumont: He won't be laid off. His contract just won't be renewed.

Sandra: It's the same thing.

Dumont: It isn't. ${ }^{25}$

We cannot simply read off the relevant baseline from the cultural context be-

23 Pettit, Republicanism, 162, 53, 54.

24 Pettit, Republicanism, 142.

25 Dardenne and Dardenne, Two Days, One Night. 
cause what counts as normal working conditions here is highly contested within the local culture.

It is clear from the history of labor struggle that there is no single, local cultural lens through which to assess other kinds of power over workers and job seekers. Workers' movements have fought to shift the background norms and expectations concerning the treatment of workers and job seekers, including the length of the working day, basic health and safety standards, the extent of holiday and sick pay, and the level of minimum wages. Conversely, employers continue to resist many of these changes and have sought to impose their own understanding of the normal condition of workers, through supporting "rightto-work" laws, legal challenges to collective bargaining, and protection for "fire at will" clauses. Of course, some common background assumptions about what counts as a worsening of a person's choice situation do still hold in most places (e.g., threatening or committing outright violence). But contextualism sheds little light on those cases we need most theoretical help to understand: the nature of the power that many employers have over hiring, firing, wage-setting, job roles, and the myriad small details that shape the everyday experience of workers.

We are now living through the latest wave of contestation over the norms and culture of work. Consider the recent rise of "platform capitalism" in which companies like Uber, Deliveroo, and TaskRabbit use proprietary digital platforms to connect workers and customers via apps. ${ }^{26}$ Local cultural standards offer no definitive criteria of judgment for determining the nature of the power these companies hold over platform workers because the relevant culture is still being formed. Should we regard these workers as independent contractors or employees owed full employment rights? Are they confronted with fewer or worse choices if their hourly wage is replaced with a piece-rate payment per task completed? Do platform companies remove or replace the choices of their workers by only allowing them to work at specific times or locations? Battles to establish what counts as the relevant default baselines here are still being waged among employers, workers, unions, the courts, and the state.

Let us suppose that consensus does arise about the baseline choices people can expect. This would still not clear a path for using conceptions of domination that depend on contextualism to diagnose the nature of power in the workplace and labor market. That is because contextualism is vulnerable to a further objection-one grounded in domination's role as a critical concept meant to give us evaluative purchase on the world around us. This critical potential is blunted by a contextualism about interference that leans heavily on local norms and culture, since these local standards are themselves subject to influence by the powerful. 
When it is no longer seen as normal for people to make certain decisions for themselves, then being deprived of them will no longer count as interference on a contextualist account. The meager options now available to them become the new baseline against which effects on their choice situation are measured, so long as these changes sufficiently saturate the local culture. For instance, if we become completely accustomed to a lack of job security and fixed working hours, then the power of bosses to fire workers at will or extract unpaid overtime at their convenience will not count as an ability to remove or replace decisions, since this would no longer actively worsen the options available to workers relative to the new normal. But the normalization of power over others should not inoculate the powerful from the charge of domination. In other words, the cultural entrenchment of domination does nothing to diminish its dominating character. On the contrary, we need a conception of domination that is able to identify and criticize those local cultures that have thoroughly acclimatized us to arbitrary power. It would be perverse if workers were made immune to domination simply because employers had engaged in such widespread and systematic deprivation of choice that people no longer thought much of the average person's powerlessness. For this reason, we should be skeptical about appealing to local cultural standards that have been shaped by the longstanding power of employers as the basis for determining whether that same power constitutes domination. ${ }^{27}$

Could an alternative to contextualism still allow us to count control over certain market offers as an ability to interfere with another's choices? The idea of the coercive offer promises to do this in many cases ${ }^{28}$ However, the offers from employers we are dealing with do not fall within the main subcategories of the coercive offer: they are not "throffers," which combine a threat and an offer; nor are they "seductive offers," which entice someone with short-term benefits without delivering long-term rewards. Are they offers under coercive circumstances? Zimmerman has argued that workers with poor bargaining positions can face "coercive wage offers" of this kind. ${ }^{29}$ But the power over recruitment that we are concerned with is the ability to withhold an offer of employment rather than

27 Can Pettit's "eyeball test" do any better? It identifies non-domination when someone can "look others in the eye without reason for the fear or deference that a power of interference might inspire; they can walk tall and assume the public status, objective and subjective, of being equal in this regard with the best" (Pettit, On the People's Terms, 84). The test makes no explicit mention of contextualist criteria for interference-but similar problems recur because it both invokes a conception of interference and relies on a standard of appropriate reasons for fear or deference for which it fails to offer a non-contextualist account. 
the power to enforce uptake of a bad offer. The ability to refuse someone a job would instead need to be understood as a coercive non-offer. Yet, many such omissions cannot be made sense of under the heading of a coercive non-offer, since the employer is often indifferent to the fate of the worker or job seeker rather than intending to get them to do something (as Dumont's power over Sandra's colleague shows). Thus, the categories of coercive offer and coercive omission will be of limited use in making sense of the power that employers hold over workers and job seekers.

We have now seen that it is harder to determine whether workers are dominated than it initially appeared. While there is a strong case for thinking that employers often possess some degree of arbitrary power over workers and job seekers, there are significant theoretical roadblocks to figuring out whether this also constitutes a power of outright interference. The contextualist account of interference that Pettit defends is difficult to apply when there is disagreement about what counts as a normal range of choices, with the history of the labor movement showing that what does and should pass as such a baseline in the workplace is often fiercely contested. But even without such disagreement, the problem with a heavily contextualist account of interference is that it can obfuscate domination of workers and job seekers that has become normalized in the local culture. Nor did appeal to coercive offers and omissions provide a comprehensive alternative. How then do we investigate whether workers and job seekers are dominated?

\section{CAPABILITY AND DOMINATION}

Neo-republicans could attempt to rebut these objections to contextualism or else turn to non-contextualist accounts of interference to shore up their accounts of domination. However, I shall argue that a more promising approach to assessing the nature of power over workers and job seekers is to adopt a conception of domination that hinges not on interference but capabilities. Domination is unfreedom that arises from subjection to another's arbitrary power-but restricting this to the arbitrary power to interfere leads to an excessively cramped understanding of dominating relationships. Someone is no less dominated when they are confronted with another agent who has the arbitrary power to determine whether they can meet their fundamental needs. Such domination does not have to be premised on an arbitrary power to interfere, where that is understood in terms of an uncontrolled ability to intentionally worsen someone's options by removing, replacing, or misrepresenting those normally available to them. You can be subject to the power of a master due to greatly needing their 
help, even if their refusal of aid would be unremarkable and so would not worsen your choices relative to the benchmark of normality.

Which needs count for domination? Limiting them to the most spartan requirements for bare life would be too restrictive. Power rooted in control over other human goods - such as social recognition and political representationcan also create subordinating relationships of mastery and servitude. Conversely, allowing any strong desire to count as such a need would be too lax. If not, the discretion to deny someone a life of untold opulence would count as outright domination, so long as they wanted this fiercely enough. In order to avoid these implausible extremes, I shall specify a set of capabilities for which it is a sufficient condition for domination that our only access to them depends on the arbitrary power of another.

Adopting the language of capabilities is not itself a radical break from orthodox neo-republicanism: Pettit already appeals to Sen's and Nussbaum's capability approaches to determine what count as the basic liberties, with these liberties fixing the scope of his republican ideal of non-domination. ${ }^{30}$ However, Pettit simply refers to "basic capabilities for local functioning," with reference to Sen and Nussbaum, without establishing why either of their rather different conceptions of capabilities provides the right focus for a republican conception of domination. ${ }^{31}$ For instance, Nussbaum's core capabilities are meant to be those without which human life would be "so impoverished that it is not worthy of the dignity of a human being." 32 While dignity is an important value, it is not clear why dignity-preserving capabilities should provide us with a criterion for domination per se. So, I shall propose a resolutely republican account of which capabilities underpin non-domination.

Modern republicans are relational egalitarians who seek to diagnose and combat relationships that subordinate some people to the autocratic power of others. Such subordination can be material, social, or political—rooted in another's control over wealth, status, or the means to rule. This suggests that domination can arise from the arbitrary power to determine access to three broad and overlapping sets of capabilities for material, social, or political functioning. These include capabilities for biological subsistence and personal development, which presuppose the availability of food, shelter, clothing, medical care, physical security, education, recreation, and rest; capabilities for social interaction,

On republicanism and the capability approach, see Pettit, "Capability and Freedom"; Qizilbash, "Some Reflections on Capability and Republican Freedom"; Laborde, "Republicanism and Global Justice."

Pettit, On the People's Terms, 112.

Nussbaum, Women and Human Development, 72. 
which presuppose the conditions for respect, association with others, and living without shame; and capabilities for political participation, which presuppose the psychological and institutional foundations for political agency, meaningful suffrage, and democratic power. We could think of these as what Elizabeth Anderson has called capabilities of "special egalitarian concern," or more loosely, as capabilitarian grounds for redistributive, recognitive, and representative justice. ${ }^{33}$ But I will name these "civic capabilities" insofar as they are necessary for citizenship among equals. ${ }^{34}$

\section{CIVIC CAPABILITIES AT WORK}

Our revised conception takes domination to arise from the arbitrary power to determine another's access to civic capabilities:

$X$ is dominated by $Y$ to the extent that $Y$ is able to arbitrarily determine whether $X$ has access to the material, social, or political capability to function as an equal citizen.

For example, the master dominates the slave because he can deprive them of all these capabilities at will and with impunity-ensuring the slave goes hungry, undereducated, shamed, or politically enfeebled. Likewise, the husband dominates the wife under coverture with respect to her material and social capabilities, since he has unaccountable power to prevent her from getting a formal education and working for a wage.

When domination is identified with arbitrary power over civic capabilities, does this fail to accommodate some plausible candidates for dominating relationships? Consider two such objections. ${ }^{35}$ First, someone might be mistaken about their fundamental needs. If they think another agent has discretion to ensure their fundamental needs are not met, then what does it matter whether their true or basic needs are really at stake after all? The feudal peasant who sincerely believes the Catholic Church's favor is necessary for eternal salvation can seem to be dominated by the clergy, irrespective of whether salvation is among his

33 Anderson, "What Is the Point of Equality?" 316.

34 Another account that understands vulnerability to domination principally in terms of control over capacities required to secure one's basic interests is Ian Shapiro's "power-based resourcism." However, I provide a more determinate and avowedly egalitarian specification of those interests than Shapiro-taking them to be the material, social, and political capabilities necessary for relationships of equality between citizens. Likewise, I reject Shapiro's non-republican claim that domination only occurs when "power is somehow abused or pressed into the service of an illegitimate purpose" ("On Non-Domination," 308 ).

I owe these objections to an anonymous reviewer for this journal. 
fundamental needs, or whether the church actually has the power to deny him it. He feels beholden, and that is enough to result in his subordination. Can a theory of civic domination make sense of cases like this?

My view is that domination occurs only when another agent has arbitrary power to determine whether someone has access to civic capabilities. Thus, I do not think that domination obtains merely because a person believes their ability to meet their fundamental needs rests in another's untied hands. But mistaken beliefs of this kind can increase the effective leverage others have over the person who holds them. The peasant who fears for his soul might thereby find it psychologically unsustainable to depart from the church's dictates on whether to pursue an education or when he can and cannot rest from work. Some of his civic capabilities do then fall within the arbitrary power of others due to misapprehensions about his needs or who can frustrate them. So, false beliefs about fundamental needs-whether they result from innocent errors or deliberate ideological manipulation - will sometimes entrench domination.

Our second objection claims people can be dominated even when they are able to meet their fundamental needs securely, since they can be subject to arbitrary power over other areas of their lives. We can fall under the sway of other people because of their control over what we want and not merely what we need. Perhaps, as we noted earlier, it would be implausible to say that domination can arise from the arbitrary power to deny someone anything they want-sex, fame, or a third slice of cake included. But why insist civic capabilities are the only levers of domination? When an ambitious and wealthy lawyer's long-sought promotion to a partnership turns on the discretion of her senior colleagues, then she may be under tremendous pressure to yield to their wishes, even if none of her civic capabilities hang in the balance. Why not take her to be dominated too?

We find similar psychological dynamics to domination in these situations, such as the pressure to fawn over influential superiors. But these are examples of what republicans have called a "corrupting dependence" arising from a discretionary ability to bestow largesse on those favored by the powerful. ${ }^{36}$ There is often something objectionable about corrupting dependence, but when civic capabilities are not at stake it falls short of the outright domination that more fatefully corrodes relationships of equality among citizens. For a political conception of non-dominated relationships, civic considerations should take precedence.

Civic domination, so understood, can take place in the absence of the arbi- 
trary power to interfere. For instance, a woman in a remote rural area can be dominated when her access to abortion is entirely dependent on the will of a single local healthcare provider with no legal or institutional obligation to facilitate this access for her. She will be at their mercy for her possession of civic capabilities relating to healthcare, even if the provider is unable to interfere sensu stricto with her choices, such that they cannot actively worsen her choice situation relative to the normal local baseline. When the manager of a small charitable shelter for the homeless has complete discretion as to whether to offer someone one of the few beds available, then she dominates them if her refusal would ensure they went without a roof over their head for the night. This amounts to arbitrary power not to extend capabilities for housing and for living without shame (at least in societies stigmatizing rough sleepers). It remains civic domination even when a refusal to admit someone to the shelter is a failure to provide them with an additional choice rather than a restriction of their normal options. Of course, judgments about whether a power to determine access to a capability is present do not have to be radically uncontextualized-what counts as shaming in one society may not in another. But such judgments do not invite problems of determinacy and criticality of the same depth as those affecting accounts that take a merely normal range of choices as their baseline for interference. The examples outlined here are relationships of domination that will not always constitute subjection to an arbitrary power of interference as understood on the contextualist model. Nevertheless, capability- and interference-centric domination can generate similar feelings of subordination and anxious precariousness. Likewise, they also incentivize deference and servility, when one person can see that another goes without the likes of shelter and bodily autonomy.

We find clear examples of this civic domination in the workplace and labor market that also count as domination on interference-centric accounts: for example, the monopsonic employer with the power to hire and fire at will, who is someone's only way of getting enough subsistence goods. But civic domination can also take place in the workplace and labor market when there is no arbitrary power to interfere or when the baseline for interference is contested. When $\mathrm{Du}$ mont has the arbitrary power not to renew Sandra's colleague's contract, then it does not matter whether this would constitute interference with the colleague's choices: he will be dominated when it would leave him without the capability to function as an equal citizen. Similarly, the monopsonic employer whose private medical insurance is a young woman's only access to abortion also subjects her to civic domination, even if access to abortion is rare in the local culture and no longer offering it would not push her below what passes for a baseline normal level of choice compared to others. This constitutes domination whether or not 
we think the employer has any moral or legal responsibility to provide someone with a job or access to medical services: the fact that they can arbitrarily ensure lack of access to civic capabilities is itself sufficient.

Monopsony and near-monopsonic conditions are more common in labor markets than is often assumed. ${ }^{37}$ But most workers and job seekers are not at the mercy of any single employer with respect to their access to civic capabilities. No one agent decides whether they can eat, learn, live without shame, or act politically: whether this happens is usually a result of a relatively uncoordinated motley of decisions by local and national governments, families and friends, charities and community associations, trade unions and law courts, and an array of private and public employers - all taking place against a background of more faceless and impersonal social processes. Thus, comparisons between employers and the near-absolute power of slave holders or tyrants risk appearing overblown.

Civic domination will be rare if it presupposes a lone autocratic who determines access to civic capabilities. But this can seem at odds with the phenomenology of work, where the experience of subordination to the sweeping authority of employers is not confined to monopsony. Consider the sense of powerlessness the writer Ivor Southwood has felt in his own low-paid and precarious manual jobs: "Where I work, doing what and for whom, for how long and how much; all these co-ordinates are arbitrary to the point of absurdity."38 He observes that "the manager increasingly comes to take the position of the customer who must be satisfied, and to whom one has to continuously sell oneself." ${ }^{39}$ Yet, none of this depends on there being only a single employer to work for. Southwood instead tell us that the position of many workers is one in which they are "taunted with the illusion of choice, like a prisoner whose jailer tosses him a bunch of keys to identical cells." ${ }^{40}$ Can a radical republicanism account for these experiences of work?

\section{STRUCTURAL DOMINATION}

Domination need not rest on the power of a single dominator. The "labor republican" movement in nineteenth century North America realized that the unfreedom they confronted as workers consisted in their systemic dependence on the owners of productive assets like land and tools more than their exposure to the caprice of any particular employer. In his groundbreaking reconstruction of

38 Southwood, Non-Stop Inertia, 70.

39 Southwood, Non-Stop Inertia, 25.

40 Southwood, The Uncomplaining Body, 9. 
labor republicanism, Alex Gourevitch uses the term "structural domination" to describe this phenomenon. He says: "Structural is the appropriate word [for the domination of these workers] because it was a form of domination arising from the background structure of property ownership and because the compulsion they felt did not force them to work for a specific individual."41 Structural domination happens when someone's socio-structural position leaves them without a reasonable alternative to being subjected to a master. Gourevitch goes on to claim that, in structural domination, "an unequal structure of control over productive assets" leads to workers being "dominated by a number of agents, but not any single, given agent in particular." ${ }^{42}$

Structural domination is contrasted with a more familiar personal domination that has a dyadic form: the latter is a relationship with a specific dominator who can exercise arbitrary power, whereas the former arises not from the power of any particular dominator but the power of many agents. Of course, social structures enable much personal domination-for instance, the personal domination of the wife by her husband under coverture depended on social background conditions, such as a specific legal tradition backed by a system of gendered social norms. But not all agents who contributed to these background structures had the direct and intentional personal power the husband could exercise. Nor did every contributing social structure constitute the kind of structural domination it is plausible to attribute to the diffuse class of men who-directly or otherwise-held the fate of most women in their hands.

While structural domination is analytically distinct from domination by a single agent, it can nevertheless generate and reinforce such personal domination. On Gourevitch's account, structurally dominated workers without a reasonable alternative to selling their labor are compelled to subject themselves to the authority of at least one employer. In contrast to the artisan, who sells the products of their labor, the waged worker sells their labor itself. Since this labor is a physical commodity inseparable from the person, this usually involves relinquishing a significant degree of control over the seller's will. It means coming under the often-considerable discretionary power of a boss, even if workers are often not completely constrained with respect to which boss that is. This boss invigilates the worker and has both the social authority and disciplinary tools to exert control over their employee's activities for much of the working day. Structural domination compels the worker into a contract of employment, and then the arbitrary power of bosses leaves them personally dominated once they are so contracted. In order to avoid these situations, the labor republicans attempted

Gourevitch, From Slavery to the Cooperative Commonwealth, 109.

Gourevitch, "Labor Republicanism and the Transformation of Work," 596, 602. 
to implement forms of cooperative labor, which sought to make workers their own masters rather than subordinating them to the authority of the owners of productive assets. ${ }^{43}$

Gourevitch's reconstruction of a labor republican understanding of structural domination is a tremendously valuable contribution to thinking through power over workers and job seekers. But it suffers from an important weak spot: an underdefended appeal to the "reasonable alternatives" available to them. Gourevitch thinks someone is structurally dominated only when they lack a reasonable alternative to subjecting themselves to the arbitrary power of a boss. When the choice is to work for a boss or starve, then it is difficult to maintain that the alternative is reasonable. But where should the line of reasonableness be drawn in more difficult cases? Much like the contextualist standard for interference, this will be highly contested. Gourevitch is skeptical that those workers and job seekers whose alternative to working for a boss is reliance on welfare benefits or an unconditional basic income can be said to escape the net of structural domination-believing that a path to exit does not necessarily secure an effective voice for workers within a company. ${ }^{44}$ This imposes a demanding threshold for what counts as a reasonable alternative to subjecting oneself to the discretionary power of an employer. Furthermore, it falls short of a criterion for determining which alternatives count as reasonable in other scenarios. Are you still structurally dominated if you have access to the capital needed to become self-employed-albeit at some risk of future bankruptcy? Will you remain structurally dominated when your wealthy spouse can decide to fund a career break whenever you grow tired of working for others? The reasonable alternative is too malleable a category to offer us determinate answers in such cases without drawing on mere intuition or a deeper account of reasonableness.

We can build upon Gourevitch's articulation of structural domination while avoiding the "no reasonable alternative" test by instead articulating a socio-structural form of civic domination:

$X$ is structurally dominated by the set of agents $Y$ to the extent their relative social positions enable the members of $Y$ to arbitrarily determine whether $X$ has the material, social, or political capability to function as an equal citizen.

Structural domination thereby comprises an arbitrary power to control access to civic capabilities that is distributed across multiple agents. Someone will be structurally dominated when their position within a social structure grants a set

Gourevitch, From Slavery to the Cooperative Commonwealth, ch. 4.

44 Gourevitch, "Labor Republicanism," 598-600. 
of other people an aggregative power over their civic standing. For example, if a group of employers can with impunity prevent someone from working by refusing to hire them, while maintaining control over the resources and opportunities they would need to provide themselves with civic capabilities, then this person will be structurally dominated. This might happen through collusion, such as drawing up a blacklist of trade union organizers, whom the employers all agree to freeze out. But an uncoordinated set of arbitrary wills is also sufficient for civic structural domination: each employer having the arbitrary power to hire and fire, with someone's economic fate and social status dependent on a series of uncontrolled but independent decisions in the hands of employers. The worker or job seeker who occupies this socio-structural position is at the mercy of the aggregated decisions of employers - subject to the disciplinary pressure of keeping at least one onside, and so not departing from any requirements they all choose to impose in common.

\section{CONCLUSION}

Are workers dominated? Sometimes. Our account of civic domination tells us someone is dominated when their access to civic capabilities is dependent on the arbitrary power of others. Workers can then be dominated when the uncontrolled decisions of employers are what determines whether they can function as equal citizens.

The domination of workers is clearest in monopsonies without a strong social safety net or stringent labor laws, such as a mining community or company town within a deregulated economy with a minimal welfare state. An employer with the discretion to hire or fire at will under these conditions-when unemployment brings hunger, eviction, or enduring shame in its wake-will have considerable arbitrary power to grant or impede the civic capabilities of local workers and job seekers. The more extensive the social safety net-with access to a greater range of civic capabilities guaranteed through measures like income redistribution or public services - then the less intense such domination will be. If someone has secure access to civic capabilities independently of employment, then even a monopsonic employer cannot dominate them. Likewise, the more robust labor laws are in limiting the uncontrolled power of employers or making this power accountable to workers, the smaller the degree of domination there will be over those workers. Of course, employers whose power is not arbitrary can still be unjust and exploitative toward workers, but they cannot be dominating.

Most workers are not beholden to a monopsonist employer, so what about 
those with a good chance of securing another job if they are sacked, quit, or not hired in the first place? Even those who can find work elsewhere are not thereby immune to a dyadic arbitrary power to determine access to civic capabilities. Changing jobs can impose significant costs that impact those capabilities: periods of unemployment can take a pecuniary toll as well as leading to a loss of the social status gained from being recognized as making a productive economic contribution; the need to become familiar with a new workplace and build new working relationships can be onerous, making workers more vulnerable to bullying and exploitation, with a throughput of staff also making it difficult to organize and exert political agency at work. That quitting is not costless can provide employers with additional leverage to make unaccountable management decisions that further sap civic capabilities: introducing more arduous working practices, restricting rest breaks, or requiring more work in the same time, with any attendant toll on physical and psychological health. Those without the independent wealth and social status to secure their civic capabilities are thus frequently exposed to personal civic domination by ordinary non-monopsonic employers too.

We need to supplement a dyadic conception of domination focusing on single dominators with a structural account of domination if we are to come to a more full understanding of the range of powers over workers and job seekers. Whenever someone is dependent on the arbitrary power of employers as a condition of securing their civic capabilities, then they will be dominated by the set of those employers able to offer or refuse them a wage or salary. Most workers in capitalist economies are structurally dominated in this way-unable to fashion themselves with the resources and opportunities necessary for political equality as citizens without the contingent and revocable support of employers. This does not necessarily imply that those employers have an obligation to ensure full employment; it simply means they have the fateful power to shape other people's lives without regard for whether those people's standing as political equals is undermined. There would be little exaggeration in claiming that workers whose socio-structural position subordinates them to the owners of productive property in this way are the victims of economic oligarchy. ${ }^{45}$

The radical republicanism outlined above gives us good reason to be worried about these forms of dominating power. Structural domination leaves our

Does this analysis make radical republicanism indistinguishable from Marxism? Domination is conceptually distinct from the alienation that Marx stresses in his early work and the form of exploitation that figures in the mature political economy. But there is significant overlap and influence between the two traditions. See Roberts, Marx's Inferno, and Leipold, Citizen Marx. 
lives in the hands of institutions we have little control over and that prioritize the interests of their stakeholders over citizens at large. This exposes workers to relationships of personal domination in which they are subordinate to specific bosses and managers. This is the lot of the London workers we encountered at the beginning of this article: vulnerable to the caprice of the labor market, which reinforces their dependence on the goodwill of their current employers, and which prompts a mixture of anxious concern and docile acquiescence to authority. If this diagnosis is sound, then it is now incumbent on republican political thought to identify the tools and politics best suited to helping these workers organize themselves and abolish the dominating power to which they-for many readers, we-are subject. Nothing less than our freedom is at stake. ${ }^{46}$

University of Roehampton tom.oshea@roehampton.ac.uk

\section{REFERENCES}

Alchian, Armen, and Harold Demsetz. "Production, Information Costs, and Economic Organization," American Economic Review 62, no. 5 (December 1972): 777-95.

Anderson, Elizabeth. "Equality and Freedom in the Workplace: Recovering Republican Insights." Social Philosophy and Policy 31, no. 2 (Spring 2015): 48-69. - Private Government: How Employers Rule Our Lives (and Why We Don't Talk About It). Princeton: Princeton University Press, 2017.

—. "What Is the Point of Equality?" Ethics 109, no. 2 (January 1999): 287337.

Anonymous. "Careless: Care Work in West London." Angry Workers of the World (blog), May 20, 2017. https://angryworkersworld.wordpress .com/2017/05/20/careless-care-work-in-west-london.

. "Don't Breakdown! Slow Down! Experiences from Sainsbury's/Wincanton Distribution Centre in Greenford." Workers Wild West, April 23, 2015. https://workerswildwest.wordpress.com/2015/04/23/workerswildwest -workers-paper-for-west-london-issue-no-2-aprilmay-2015.

. "Soldering On: Report on Working in a 3D-Printer Manufacturing Plant in London." Angry Workers of the World (blog), March 24, 2017. https://

46 Thanks to Alex Bryan, Adam Fusco, Bruno Leipold, and two anonymous referees for this journal for comments on earlier versions, and to James Hickson for helpful discussions about workplace republicanism. 
angryworkersworld.wordpress.com/2017/03/24/soldering-on-report-on -working-in-a-3d-printer-manufacturing-plant-in-london.

Azar, José, Ioana Marinescu, and Marshall Steinbaum. "Labor Market Concentration." National Bureau of Economic Research, Working Paper 24147, 2017. https://www.nber.org/papers/w24147.

Breen, Keith. "Freedom, Republicanism, and Workplace Democracy." Critical Review of International Social and Political Philosophy 18, no. 4 (2015): 470-85. Cunliffe, Marcus. Chattel Slavery and Wage Slavery: The Anglo-American Context 1830-1860. Athens, GA: University of Georgia Press, 1979.

Dagger, Richard. "Neo-Republicanism and the Civic Economy." Politics, Philosophy and Economics 5, no. 2 (2006): 151-73.

Dardenne, Luc, Jean-Pierre Dardenne, dirs. Two Days, One Night. Diaphenne Films, 2014.

Digest of Justinian. Latin text edited by Theodor Mommsen with the aid of Paul Krueger. English translation edited by Alan Watson. Philadelphia: University of Pennsylvania Press, 1985.

Garrison, William Lloyd. "Is the Cause Onward." Independent, January 14, 1869. González-Ricoy, Iñigo. “The Republican Case for Workplace Democracy.” Social Theory and Practice 40, no. 2 (April 2014): 232-54.

Gourevitch, Alex. From Slavery to the Cooperative Commonwealth: Labor and Republican Liberty in the Nineteenth Century. Cambridge: Cambridge University Press, 2015.

_ .Labor Republicanism and the Transformation of Work." Political Theory 41, no. 4 (August 2013): 591-617.

Honohan, Iseult. Civic Republicanism. London: Routledge, 2002.

Hsieh, Nien-Hê. "Rawlsian Justice and Workplace Republicanism." Social Theory and Practice 31, no. 1 (January 2005): 115-42.

Jugov, Tamara. "Systemic Domination as Ground of Justice." European Journal of Political Theory. Published ahead of print, February 27, 2017. https:// doi.org/10.1177/1474885117690905.

Laborde, Cécile. Critical Republicanism: The Hijab Controversy and Political Philosophy. Oxford: Oxford University Press, 2008.

—. "Republicanism and Global Justice: A Sketch." European Journal of Political Theory 9, no. 1 (January 2010): 48-69.

Leipold, Bruno. "Citizen Marx: The Relationship between Karl Marx and Republicanism" $\mathrm{PhD}$ diss., University of Oxford, 2017.

Lovett, Frank. A General Theory of Domination and Justice. Oxford: Oxford University Press, 2010. 
— . "What Counts as Arbitrary Power?" Journal of Political Power 5 (2012): $137-52$.

MacGilvray, Eric. The Invention of Market Freedom. Cambridge: Cambridge University Press, 2011.

Nussbaum, Martha. Women and Human Development: The Capabilities Approach. Cambridge: Cambridge University Press, 2000.

Patterson, Orlando. Slavery and Social Death: A Comparative Study. Boston: Harvard University Press, 1982.

Pettit, Philip. "Capability and Freedom: A Defence of Sen." Economics and Philosophy 17, no. 1 (April 2001): 1-20.

- "Freedom in the Market." Politics, Philosophy and Economics 5, no. 2 (June 2006): 131-49.

- On the People's Terms: A Republican Theory and Model of Democracy. Cambridge: Cambridge University Press, 2012.

- Republicanism: A Theory of Freedom and Government. Oxford: Clarendon Press, 1997.

Qizilbash, Mozaffar. "Some Reflections on Capability and Republican Freedom." Journal of Human Development and Capacities 17, no. 1 (2016): 22-34.

Roberts, William Clare. Marx's Inferno: The Political Theory of Capital. Princeton: Princeton University Press, 2017.

Shapiro, Ian. "On Non-Domination." University of Toronto Law Journal 62, no. 3 (Summer 2012): 293-335.

Skinner, Quentin. "Classical Liberty and the Coming of the English Civil War." In Republicanism: A Shared European Heritage, vol. 2, edited by Martin van Gelderen and Quentin Skinner, 9-28. Cambridge: Cambridge University Press, 2002.

- "Freedom as the Absence of Arbitrary Power." In Republicanism and Political Theory, edited by Cécile Laborde and John Maynor, 83-101. Oxford: Blackwell, 2008.

Southwood, Ivor. Non-Stop Inertia. Alresford: Zero Books, 2011. The Uncomplaining Body. London: Manual Labours, 2015.

Sparling, Robert. "Political Corruption and the Concept of Dependence in Republican Thought." Political Theory 41, no. 4 (August 2013): 618-47.

Srnicek, Nick. Platform Capitalism. Cambridge: Polity Press, 2017.

Taylor, Robert. Exit Left: Markets and Mobility in Republican Thought. Oxford: Oxford University Press, 2017.

Wertheimer, Alan. Consent to Sexual Relations. Cambridge: Cambridge University Press, 2004. 
White, Stuart. "The Republican Critique of Capitalism." Critical Review of International Social and Political Philosophy 14, no. 5 (2011): 561-79.

Zimmerman, David. "Coercive Wage Offers." Philosophy and Public Affairs 10, no. 2 (Spring 1981): 121-45. 